\title{
COMMENTARY
}

\section{Good-bye CRRT, here comes SLED? ... not so fast!}

\author{
Michael Joannidis* \\ See related research by Schwenger et al., http://ccforum.com/content/16/4/R140
}

\begin{abstract}
In the continuing dispute about the superiority of either intermittent or continuous renal replacement therapy for the critically ill, hybrid methods such as sustained low-efficiency dialysis (SLED) combining the advantages of both modalities - that is, excellent hemodynamic stability and low costs - receive growing attention. The study by Schwenger and colleagues is the first randomized trial indicating that there may be no significant difference in survival at 90 days between patients treated with SLED as compared with those treated with continuous venovenous hemofiltration.
\end{abstract}

The study by Schwenger and colleagues in a previous issue of Critical Care may add some new aspects to the rapid evolution of renal replacement therapies in the critically ill over the last three decades [1]. The first major breakthrough occurred in 1977 when continuous renal replacement therapy (CRRT) was created by the appearance of arterio-venous hemofiltration, with the original intention of fluid removal in unstable patients with diuretic resistance [2]. This approach turned out to also provide detoxification in uremic patients with superior cardiovascular stability compared with conventional intermittent hemodialysis available at that time [3]. With the evolution of pump-driven continuous veno-venous hemofiltration $(\mathrm{CVVH})$, higher ultrafiltration rates and thus doses became achievable, which could be even further augmented by adding diffusion typical for continuous hemodiafiltration.

Triggered by the issue of costs, which are mainly driven by the requirement for sterilized solution bags for substitution fluids or dialysates in CRRT $[4,5]$, the concept of extended daily dialysis was developed using a conventional dialysis machine, with treatment times of

*Correspondence: michael.joannidis@i-med.ac.at

Medical Intensive Care Unit, Department of General Internal Medicine I, Medical University Innsbruck, Anichstrasse 35, 6020 Innsbruck, Austria around 8 hours allowing for slower fluid and toxin removal [6]. Next, the invention of a single-batch dialysis system with online dialysate production, providing sustained low-efficiency dialysis (SLED), allowed one to replace expensive and complex dialysis machines requiring operation by dialysis nurses [7], showing similar hemodynamic stability and efficacy in terms of urea removal as CVVH [8].

The well-designed single-center study by Schwenger and colleagues is the first randomized trial investigating the outcome of critically ill patients treated by SLED compared with those treated by CVVH at a dose of $35 \mathrm{ml} / \mathrm{kg} /$ hour [1]. Achieving the same survival at 90 days, SLED also showed a tendency towards shorter ICU stays and less ventilation days at significantly lower costs than CVVH. The study has several implications, however. First, in terms of outcome and cardiovascular stability, SLED and CVVH appear to be quite equivalent. Furthermore, since average treatment durations were quite similar for both modalities (14.9 hours vs. 19.9 hours for SLED and CVVH, respectively), the study indicates that convection provided by hemofiltration possibly does not confer significant benefit over diffusion provided by dialysis, which may also be concluded from other trials [9]. Finally, the slightly longer days on ventilation as well as longer ICU stay reported for patients treated with CVVH may reflect a major disadvantage of CRRT requiring patients to be attached to the extracorporeal circuit around the clock, thus limiting early physiotherapy and mobilization. The latter findings, however, were barely statistically significant and definitely require further substantiation.

So finally, we apparently have a well-tolerated, efficient and potentially cheap modality at hand. In times of emerging cost restraints, should this not become the new standard for renal replacement therapy in the ICU?

A closer look at the study still leaves us with some hesitation. First of all, dialysis using a batch dialysis system requires a central dialysate preparation unit in a separate room with significant investments. The proportional costs for a single renal replacement therapy treatment depend on the number of machines in use as well as the number of treatments, and would be much higher for units with lower frequencies. Furthermore, 
insufficient purity of water and contamination of the dialysate have been a reported problem for dialysis units [10].

The second issue is the quite low average filter survival of roughly 20 hours reported for CVVH by Schwenger and colleagues [1] - implicating frequent clotting and filter changes, resulting in increased nursing time for setting up new circuits and enhanced blood loss. This observation was probably due to the unusually high filtration fractions $>40 \%$ resulting from low average blood flows of $102 \mathrm{ml} /$ minute as well as the use of unfractionated heparin for anticoagulation in the CVVH group. Increasing filter survival applying lower filtration fractions and using low molecular weight heparin for anticoagulation probably would have reduced the costs for CVVH [11]. Furthermore, over the last few years regional citrate anticoagulation has become available for all modes of CRRT and has been recommended by the KDIGO 2012 guidelines [12], making average filter survival $>72$ hours easily achievable $[13,14]$, reducing blood transfusion requirements [13] as well as providing better biocompatibility and possibly survival $[15,16]$. Last, but not least, current dose recommendations are considerably lower, with 20 to $25 \mathrm{ml} / \mathrm{kg} /$ hour reducing the amount of substitution fluid required. A cost calculation regarding all these aspects would show far less superiority of SLED over CVVH, if any at all.

Therefore, although SLED holds some promise for becoming the new low-cost carrier for renal replacement therapy, we still need further stringent economic as well clinical evaluation of SLED compared with CRRT performed in a current state-of-the-art way before any general changes to treatment patterns can be recommended on solid grounds.

\section{Abbreviations}

CRRT, continuous renal replacement therapy; $\mathrm{CVVH}$, continuous veno-venous hemofiltration; SLED, sustained low-efficiency dialysis.

\section{Competing interests}

$\mathrm{MJ}$ received speaker's and consulting honoraria from Baxter, Fresenius and Gambro.

Published: 5 November 2012
References

1. Schwenger V, Weigand MA, Hoffmann O, Dikow R, Kihm LP, Seckinger J, Miftari N, Schaier M, Hofer S, Haar C, Nawroth PP, Zeier M, Martin E, Morath C: Sustained low efficiency dialysis using a single-pass batch system in acute kidney injury - a randomized interventional trial: the REnal Replacement Therapy Study in Intensive Care Unit PatiEnts. Crit Care 2012, 16:R140.

2. Kramer P, Wigger W, Rieger J, Matthaei D, Scheler F: [Arteriovenous haemofiltration: a new and simple method for treatment of over-hydrated patients resistant to diuretics]. Klin Wochenschr 1977, 55:1121-1122.

3. Stokke T, Kramer P, Schrader J, Grone HJ, Burchardi H: [Continuous arteriovenous hemofiltration (CAVH)]. Anaesthesist 1982, 31:579-583.

4. Ronco C, Bellomo R, Homel P, Brendolan A, Dan M, Piccinni P, La Greca G: Effects of different doses in continuous veno-venous haemofiltration on outcomes of acute renal failure: a prospective randomised trial. Lancet 2000, 356:26-30.

5. Saudan P, Niederberger M, De SS, Romand J, Pugin J, Perneger T, Martin PY: Adding a dialysis dose to continuous hemofiltration increases survival in patients with acute renal failure. Kidney Int 2006, 70:1312-1317.

6. Kumar VA, Craig M, Depner TA, Yeun JY: Extended daily dialysis: a new approach to renal replacement for acute renal failure in the intensive care unit. Am J Kidney Dis 2000, 36:294-300.

7. Lonnemann G, Floege J, Kliem V, Brunkhorst R, Koch KM: Extended daily veno-venous high-flux haemodialysis in patients with acute renal failure and multiple organ dysfunction syndrome using a single path batch dialysis system. Nephrol Dial Transplant 2000, 15:1189-1193.

8. Kielstein JT, Kretschmer U, Ernst T, Hafer C, Bahr MJ, Haller H, Fliser D: Efficacy and cardiovascular tolerability of extended dialysis in critically ill patients: a randomized controlled study. Am J Kidney Dis 2004, 43:342-349.

9. Joannidis M: Why did dose trials fail? Contrib Nephrol 2011, 174:222-231.

10. Glorieux G, Neirynck N, Veys N, Vanholder R: Dialysis water and fluid purity: more than endotoxin. Nephrol Dial Transplant 2012. [Epub ahead of print]

11. Joannidis M, Kountchev J, Rauchenzauner M, Schusterschitz N, Ulmer H, Mayr A, Bellmann R: Enoxaparin vs. unfractionated heparin for anticoagulation during continuous veno-venous hemofiltration: a randomized controlled crossover study. Intensive Care Med 2007, 33:1571-1579.

12. Kidney Disease: Improving Global Outcomes (KDIGO) Acute Kidney Injury Work Group. KDIGO Clinical Practice Guideline for Acute Kidney Injury. Kidney Int 2012, Suppl 2:1-138.

13. Kutsogiannis DJ, Gibney RT, Stollery D, Gao J: Regional citrate versus systemic heparin anticoagulation for continuous renal replacement in critically ill patients. Kidney Int 2005, 67:2361-2367.

14. Monchi M, Berghmans D, Ledoux D, Canivet JL, Dubois B, Damas P: Citrate vs. heparin for anticoagulation in continuous venovenous hemofiltration: a prospective randomized study. Intensive Care Med 2004, 30:260-265.

15. Oudemans-van Straaten HM, Kellum JA, Bellomo R: Clinical review: anticoagulation for continuous renal replacement therapy - heparin or citrate? Crit Care 2011, 15:202.

16. Oudemans-van Straaten HM, Bosman RJ, Koopmans M, van d, V, Wester JP, van der Spoel Jl, Dijksman LM, Zandstra DF: Citrate anticoagulation for continuous venovenous hemofiltration. Crit Care Med 2009, 37:545-552.

doi:10.1186/cc11651

Cite this article as: Joannidis M: Good-bye CRRT, here comes SLED? ... not so fast! Critical Care 2012, 16:167. 